\title{
International Standards for a Safe Practice of Anesthesia 2010
}

\author{
Alan F. Merry, FANZCA · Jeffrey B. Cooper, PhD • \\ Olaitan Soyannwo, MMed • Iain H. Wilson, FRCA • \\ John H. Eichhorn, MD
}

Received: 9 July 2010/Accepted: 16 August 2010/Published online: 21 September 2010

(C) The Author(s) 2010. This article is published with open access at Springerlink.com

These standards ${ }^{\mathrm{A}}$ are recommended for anesthesia professionals throughout the world. They are intended to provide guidance and assistance to anesthesia professionals, their professional societies, hospital and facility administrators, and governments for improving and maintaining the quality and safety of anesthesia care. They were adopted by the World Federation of Societies of Anaesthesiologists on the $13^{\text {th }}$ June 1992 , and revisions were ratified on $5^{\text {th }}$ March 2008 and on $19^{\text {th }}$ March 2010.

For some anesthesia services, groups, and departments these standards will represent a future goal, while for others they may already have been implemented and be regarded as mandatory. It is recognized that in some settings facing challenges in resources and organization, not even those standards regarded as mandatory are met at present. The

This article is reproduced with permission from the World Federation of Societies of Anaesthesiologists (WFSA) and appeared previously on the WFSA website (http://www.anaesthesiologists.org/).

A.F. Merry, J.B. Cooper, O. Soyannwo, I.H. Wilson, J.H. Eichhorn, these authors are in the Safe Anesthesia Working Group of the World Health Organization's Safe Surgery Saves Lives Global Challenge A.F. Merry is Chair of the Quality and Safety Committee and I.H. Wilson is Chair of the Publications Committee of the World Federation of Societies of Anaesthesiologists.

\section{A. F. Merry, FANZCA $(\square)$}

Department of Anaesthesiology, University of Auckland, Private Bag 92019, Auckland 1142, New Zealand

e-mail: a.merry@auckland.ac.nz

\section{A. F. Merry, FANZCA}

Department of Anaesthesia, Auckland City Hospital, Private Bag 92019, Auckland 1142, New Zealand

\section{J. B. Cooper, $\mathrm{PhD}$}

Department of Anesthesia, Critical Care and Pain Medicine,

Massachusetts General Hospital, Boston, MA, USA provision of anesthesia under such circumstances should be restricted to procedures which are absolutely essential for the urgent or emergency saving of life or limb, and every effort should be made by those responsible for the provision of healthcare in these areas and settings to ensure that the standards are met. Provision of anesthesia care at standards lower than those outlined as mandatory for anesthesia for elective surgical procedures simply cannot be construed as safe acceptable practice. The most important standards relate to individual anesthesia professionals. Monitoring devices play an important part in safe anesthesia as extensions of human senses and clinical skills rather than their replacement.

Adopting the standardized language of the World Health Organization, minimum standards that would be expected in all anesthesia care for elective surgical procedures are

\footnotetext{
${ }^{\mathrm{A}}$ For the genesis and evolution of these standards, please see the accompanying article: Merry AF, Cooper JB, Soyannwo O, Wilson $\mathrm{IH}$, Eichhorn, JH. An iterative process of global quality improvement: the International Standards for a Safe Practice of Anesthesia 2010. Canadian Journal of Anesthesia 2010;57(11).

O. Soyannwo, MMed

Department of Anaesthesia, University of Ibadan College of Medicine/University College Hospital, Ibadan, Nigeria

I. H. Wilson, FRCA

Royal Devon and Exeter NHS Foundation Trust,

Exeter, Devon, UK

J. H. Eichhorn, MD

Department of Anesthesiology, University of Kentucky College of Medicine and Medical Center, Lexington, KY, USA
} 
termed "HIGHLY RECOMMENDED" and these are the functional equivalent of "mandatory" standards. These HIGHLY RECOMMENDED standards, indicated in bold type, are applicable throughout any elective procedure, from patient evaluation until recovery (it is recognized, however, that immediate life-saving measures always take precedence in an emergency). In the judgement of the WFSA, these are the minimum standards for anesthesia for a "necessary" procedure (rather than essential and/or emergency) in settings where resources are extremely limited. This does not imply that these standards on their own are ideal or even acceptable in more adequately resourced settings. These HIGHLY RECOMMENDED (functional equivalent of mandatory) standards and (regarding facilities, equipment, and medications) the parallel prescription for "Level 1" or "basic" infrastructure are relevant to any healthcare environment anywhere in which general or regional anesthetics are administered, but not to a setting where superficial procedures involving local anesthetics only are performed. Additional elements of the anesthesia standards should be implemented as resources, organization, and training permit, yielding this paradigm:

\begin{tabular}{lcl}
\hline Anesthesia standards (in order of adoption) & Setting & Infrastructure \\
\hline HIGHLY RECOMMENDED & Level & Basic \\
& 1 & \\
HIGHLY & Level & Intermediate \\
RECOMMENDED + RECOMMENDED & 2 & \\
HIGHLY & Level & Optimal \\
RECOMMENDED + RECOMMENDED & 3 & \\
+ Suggested & & \\
\hline
\end{tabular}

See Table 1 for a detailed outline of the integration of the practice standards with the levels of facilities/infrastructure. The goal always in any setting is to practice to the highest possible standards, specifically exceeding those prescribed if that can be accomplished. In spite of some facilities' limitations, it may be possible to implement elements of the RECOMMENDED standards even in a "basic" setting and, likewise, to implement elements of the Suggested standards even in an "intermediate" setting. The goal is always the best care possible and ongoing improvement by meeting and exceeding the standards for safe practice of anesthesia, starting with all providers meeting the HIGHLY RECOMMENDED standards and striving to meet as many of the RECOMMENDED and Suggested standards as well.

It is anticipated that these standards and the setting/ infrastructure specifications will be revised as practice and technology evolve.
International Standards for a Safe Practice of Anesthesia 2010

General standards

\section{Professional status}

Anesthesia services are a vital component of basic healthcare requiring appropriate resources. The WFSA views anesthesia as a medical practice. Medically trained anesthesia specialists should be trained and accredited with clinical and administrative autonomy. When anesthesia is provided by non-medical personnel, these providers should be appropriately trained and accredited as well as directed and supervised by medically qualified specialist anesthesia professionals.

\section{Professional organizations}

Anesthesia professionals should form appropriate organizations at local, regional, and national levels for the setting of standards of practice, supervision of training and continuing education/continuing professional development with appropriate certification and accreditation, and general promotion of anesthesia as an independent professional specialty. These organizations should form links with appropriate groups within the region and/or country and internationally.

\section{Training, certification, and accreditation}

Adequate time, facilities, and financial support should be available for professional training, both initial and continuing, to ensure that an adequate standard of knowledge, expertise, and practice is attained and maintained. Formal certification of training and accreditation to practice is RECOMMENDED.

\section{Records and statistics}

A record of the details of each anesthetic should be made and preserved with the patient's medical record. This should include details of the pre-operative assessment and the post-operative course. It is RECOMMENDED that individuals, departments, and regional and national groups collect cumulative data to facilitate the progressive enhancement of the safety, efficiency, effectiveness, and appropriateness of anesthesia care.

\section{Peer review and incident reporting}

Institutional, regional, and/or national mechanisms to provide a continuing review of anesthetic practice 
Table 1 Guide to Infrastructure, Supplies and Anesthesia Standards at Three Levels of Health Care Facility Infrastructure and Supplies

Level 1 (Should meet at least $H I G H L Y$

RECOMMENDED anesthesia standards)

Small hospital / health centre

Rural hospital or health centre with a small number of beds (or urban location in an extremely disadvantaged area); sparsely equipped operating room (OR) for "minor" procedures

Provides emergency measures in the treatment of $90-95 \%$ of trauma and obstetrics cases (excluding cesarean section)

Referral of other patients (for example, obstructed labour, bowel obstruction) for further management at a higher level

\section{Essential Procedures}

Normal delivery

Uterine evacuation

Circumcision

Hydrocele reduction, incision and drainage

Wound suturing

Control of hemorrhage with pressure dressings

Debridement and dressing of wounds

Temporary reduction of fractures

Cleaning or stabilization of open and closed fractures

Chest drainage (possibly) Abscess drainage

\section{Personnel}

Paramedical staff/anesthetic officer (including on-the-job training) who may have other duties as well

Nurse-midwife

\section{Drugs}

Ketamine $50 \mathrm{mg} / \mathrm{ml}$ injection

Lidocaine $1 \%$ or $2 \%$

Diazepam $5 \mathrm{mg} / \mathrm{ml}$ injection, $2 \mathrm{ml}$ or midazolam $1 \mathrm{mg} / \mathrm{ml}$ injection, $5 \overline{\mathrm{ml}}$

Pethidine $50 \mathrm{mg} / \mathrm{ml}$ injection, $2 \mathrm{ml}$

Morphine $10 \mathrm{mg} / \mathrm{ml}, 1 \mathrm{ml}$

Epinephrine (Adrenaline) $1 \mathrm{mg}$

Atropine $0.6 \mathrm{mg} / \mathrm{ml}$

Appropriate inhalation anesthetic if vaporizer available
Level 2 (Should meet at least HIGHLY

RECOMMENDED and RECOMMENDED

anesthesia standards) District/provincial

hospital

District or provincial hospital (e.g. with $100-300$ beds) and adequately equipped major and minor operating rooms

Short term treatment of $95-99 \%$ of the major life threatening conditions

\section{Essential Procedures}

Same as Level 1 with the following additions: Cesarean section

Laparotomy (usually not for bowel obstruction)

Amputation

Hernia repair

Tubal ligation

Closed fracture treatment and application of plaster of Paris

Acute open orthopedic surgery: e.g internal fixation of fractures

Eye operations, including cataract extraction

Removal of foreign bodies: e.g. in the airway

Emergency ventilation and airway management for referred patients such as those with chest and head injuries

\section{Personnel}

One or more trained anesthesia professionals

District medical officers, senior clinical officers, nurses, midwives

Visiting specialists or resident surgeon and/or obstetrician/ gynecologist

\section{Drugs}

Same as Level 1, but also:

Thiopental $500 \mathrm{mg} / 1 \mathrm{~g}$ powder or propofol.

Suxamethonium bromide $500 \mathrm{mg}$ powder

Pancuronium

Neostigmine $2.5 \mathrm{mg}$ injection

Ether, halothane or other inhalation anesthetics

Lidocaine $5 \%$ heavy spinal solution, $2 \mathrm{ml}$

Bupivacaine $0.5 \%$ heavy or plain, $4 \mathrm{ml}$

Hydralazine $20 \mathrm{mg}$ injection
Level 3 (Should meet at least HIGHLY RECOMMENDED, RECOMMENDED and SUGGESTED anesthesia standards) Referral hospital

A referral hospital of 300-1000 or more beds with basic intensive care facilities.

Treatment aims are the same as for Level 2, with the addition of: Ventilation in OR and ICU

Prolonged endotracheal intubation

Thoracic trauma care

Hemodynamic and inotropic treatment

Complex neurological and cardiac surgery

Basic ICU patient management and monitoring for up to 1 week : all types of cases, but possibly with limited provision for: Multi-organ system failure

Hemodialysis

Prolonged respiratory failure

Metabolic care or monitoring

\section{Essential Procedures}

Same as Level 2 with the following additions:

Facial and intracranial surgery

Bowel surgery

Pediatric and neonatal surgery

Thoracic surgery

Major eye surgery

Major gynecological surgery, e.g. vesicovaginal repair

\section{Personnel}

Clinical officers and specialists in anesthesia and surgery

\section{Drugs}

Same as Level 2 with these additions:

Propofol

Nitrous oxide

Various modern neuromuscular blocking agents

Various modern inhalation anesthetics

Various inotropic agents

Various intravenous antiarrhythmic agents

Nitroglycerine for infusion

Calcium chloride $10 \% 10$ im injection 
Table 1 continued

Level 1 (Should meet at least HIGHLY

RECOMMENDED anesthesia standards)

Small hospital / health centre
Level 2 (Should meet at least HIGHLY

RECOMMENDED and RECOMMENDED anesthesia standards) District/provincial hospital

Furosemide $20 \mathrm{mg}$ injection

Dextrose 50\% $20 \mathrm{ml}$ injection

Aminophylline $250 \mathrm{mg}$ injection

Ephedrine 30/50 mg ampoules

Hydrocortisone

(?) Nitrous oxide

\section{Equipment: capital outlay}

Adult and pediatric self-inflating breathing bags with masks

Foot-powered suction

Stethoscope, sphygmomanometer, thermometer

Pulse oximeter

Oxygen concentrator or tank oxygen and a draw-over vaporizer with hoses

Laryngoscopes, bougies

\section{Equipment: disposable}

Examination gloves

IV infusion/drug injection equipment

Suction catheters size 16 FG

Airway support equipment, including airways and tracheal tubes

\section{Equipment: capital outlay}

Complete anesthesia, resuscitation and Reliable oxygen sources

Vaporizer(s)

Hoses and valves

Bellows or bag to inflate lungs

Face masks (sizes 00-5)

Work surface and storage

Pediatric anesthesia system

Oxygen supply failure alarm; oxygen analyzer

Adult and pediatric resuscitator sets

Pulse oximeter, spare probes, adult and pediatric*

Capnograph*

Defibrillator (one per O.R. suite / ICU)*

ECG (electrocardiograph) monitor*

Laryngoscope, Macintosh blades 1-3(4)

Oxygen concentrator[s] [cylinder]

Foot or electric suction

IV pressure infusor bag

Adult and pediatric resuscitator sets

Magill forceps (adult and child), intubation stylet and/or bougie

Spinal needles $25 \mathrm{G}$

Nerve stimulator

Automatic non-invasive blood pressure monitor

\section{Equipment: disposable}

ECG electrodes

IV equipment (minimum fluids: normal saline, Ringer's lactate and dextrose $5 \%)$

Pediatric giving sets

Suction catheters size 16 FG

Sterile gloves sizes 6-8 airway management systems including:
Level 3 (Should meet at least $H I G H L Y$ RECOMMENDED, RECOMMENDED and SUGGESTED anesthesia standards) Referral hospital

Potassium chloride $20 \% 10 \mathrm{ml}$ injection for infusion

\section{Equipment: capital outlay}

Same as Level 2 with these additions (per operating room or per ICU bed, except where stated):

ECG (electrocardiograph) monitor*

Anesthesia ventilator, reliable electric power source with manual override

Infusion pumps (2 per bed)

Pressure bag for IV infusion

Electric or pneumatic suction

Oxygen analyzer*

Thermometer [temperature probe*]

Electric warming blanket

Electric overhead heater

Infant incubator

Laryngeal mask airways sizes 2, 3, 4 (3 sets per O.R)

Intubating bougies, adult and child (1 set per O.R)

Anesthetic agent (gas and vapour) analyser

Depth of anesthesia monitors are being increasingly recommended for cases at high risk of awareness but are not standard monitoring in many countries.

\section{Equipment: disposable}

Same as Level 2 with these additions:

Ventilator circuits

Yankauer suckers

Giving sets for IV infusion pumps

Disposables for suction machines 
Table 1 continued

\begin{tabular}{|c|c|c|}
\hline $\begin{array}{l}\text { Level } 1 \text { (Should meet at least } H I G H L Y \\
R E C O M M E N D E D \text { anesthesia standards) } \\
\text { Small hospital / health centre }\end{array}$ & $\begin{array}{l}\text { Level } 2 \text { (Should meet at least } H I G H L Y \\
R E C O M M E N D E D \text { and } R E C O M M E N D E D \\
\text { anesthesia standards) District/provincial } \\
\text { hospital }\end{array}$ & $\begin{array}{l}\text { Level } 3 \text { (Should meet at least } H I G H L Y \\
\text { RECOMMENDED, RECOMMENDED and } \\
\text { SUGGESTED anesthesia standards) Referral } \\
\text { hospital }\end{array}$ \\
\hline Oral and nasal airways & $\begin{array}{l}\text { Nasogastric tubes sizes } 10-16 \mathrm{FG} \\
\text { Oral airways sizes } 000-4 \\
\text { Tracheal tubes sizes } 3-8.5 \mathrm{~mm} \\
\text { Spinal needles sizes } 22 \mathrm{G} \text { and } 25 \mathrm{G} \\
\text { Batteries size C }\end{array}$ & $\begin{array}{l}\text { Disposables for capnography, } \\
\text { oxygen analyzer, in accordance } \\
\text { with manufacturers' } \\
\text { specifications: } \\
\text { Sampling lines } \\
\text { Water traps } \\
\text { Connectors } \\
\text { Filters - Fuel cells }\end{array}$ \\
\hline
\end{tabular}

* It is preferable to combine these modalities all in one unit

Note: drug concentrations and quantities are indicative only. All equipment should be appropriate for patients' age and size

should be instituted. Regular confidential discussion of appropriate topics and cases with multidisciplinary professional colleagues should take place. Protocols should be developed to ensure that deficiencies in individual and collective practice are identified and rectified. An anonymous incident reporting system with case analysis and resulting suggested remedies is RECOMMENDED.

\section{Workload}

A sufficient number of trained anesthesia professionals should be available so that individuals may practice to a high standard without undue fatigue or physical demands. Time should be allocated for education, professional development, administration, research, and teaching.

\section{Personnel}

An anesthesia professional should be dedicated to each patient and be immediately present throughout each anesthetic (general, regional, or monitored sedation), and should be responsible for the transport of the patient to the post-anesthesia recovery facility and the transfer of care to appropriately trained personnel. An anesthesia professional should retain overall responsibility for the patient during the recovery period and should be readily available for consultation until the patient has made an adequate recovery. If responsibility for care is transferred from one anesthesia professional to another, a "handover protocol" should be followed, during which all relevant information about the patient's history, medical condition, anesthetic status, and plan should be communicated. An anesthesia professional should ensure, if aspects of direct care are delegated before, during, or after an anesthetic, that the person to whom responsibility is delegated is both suitably qualified and conversant with relevant information regarding the anesthetic and the patient. Where it is impossible for this standard to be attained and the surgeon or other individual assumes responsibility for the anesthetic, these arrangements should be reviewed and audited by an appropriately trained anesthesia professional.

\section{Facilities, equipment, and medications}

Appropriate equipment and facilities, adequate both in quantity and quality, should be present wherever anesthesia and recovery from it is undertaken, including outside traditional hospital operating room suites, such as procedure or imaging suites and outpatient facilities or offices. In-service training and verification of an individual's ability to use a specific piece of equipment correctly and safely is required. Formal certification as documentation of this process is Suggested. A list of facilities, infrastructure elements and supplies at the three levels and suggestions as to the order in which additions should be made when possible as resources permit is presented in Table 1. Anesthesia equipment should conform to relevant national and international standards. Appropriate anesthetic, resuscitative, and adjuvant medications are required at each level.

\section{World Health Organization 2009 Safe Surgery Checklist}

The 2009 Safe Surgery Checklist (http://www.who.int/ patientsafety/information_centre/documents/en/index.html) consists of evidence based vital checks in 3 phases: before starting anesthesia, before starting surgery and at the end of surgery. The use of the checklist (locally modified if 
appropriate) in anesthesia care is HIGHLY RECOMMENDED.

Peri-anesthetic care and monitoring standards

The first and most important component of peri-anesthetic care, including monitoring of the anesthesia delivery system and the patient, is the continuous presence of a vigilant anesthesia professional during anesthesia. In addition to use of monitoring technology, careful continuous clinical observation is required because equipment may not detect clinical deterioration as rapidly as the skilled professional. If an emergency requires the brief temporary absence of the primary anesthesia professional, judgment must be exercised comparing the emergency with the anesthetized patient's condition and in the selection of the person left responsible for the anesthetic during the temporary absence.

\section{Pre-anesthetic care}

The patient must be evaluated by an anesthesia professional prior to administration of anesthesia and an appropriate anesthetic plan formulated. The anesthesia professional must ensure that all necessary equipment is present and functions correctly prior to initiation of anesthesia care. The anesthesia professional should ensure that assistance is available as needed and that the assistant is competent at, or has been instructed in, the necessary tasks. The development of protocols and check-lists to facilitate such verification is RECOMMENDED.

\section{Pre-anesthesia checks}

A. An appropriate "pre-list check," which has been established in each health care institution providing anesthesia services, of the anesthesia system, facilities, equipment, and supplies should be performed prior to the start of each operating list.

B. The relevant components of the World Health Organization Safe Surgery Checklist should be performed.

C. An appropriate "pre-patient check" (such as presented in the attached Pre-anesthetic check list) which has been established in each health care institution providing anesthesia services, of the anesthesia system and anesthetizing location should be executed prior to each anesthetic.
3. Monitoring during anesthesia

A. Oxygenation

(i) Oxygen supply

Supplemental oxygen is HIGHLY RECOMMENDED for all patients undergoing general anesthesia. The anesthesia professional should verify the integrity of the oxygen supply. It is RECOMMENDED that the inspired oxygen concentration be monitored throughout each anesthetic with an instrument fitted with a low oxygen concentration alarm. An oxygen supply failure alarm and a device protecting against the delivery of an hypoxic gas mixture are RECOMMENDED. Systems with interlocks (tank yokes, hose connections, etc.) should be used to prevent misconnection of gas sources.

\section{(ii) Oxygenation of the patient}

Tissue oxygenation should be monitored continuously. For visual examination, adequate illumination and exposure of the patient should be ensured whenever practicable. Continuous use of pulse oximetry is HIGHLY RECOMMENDED.

\section{B. Airway and ventilation}

The adequacy of the airway and ventilation should be continuously monitored at least by observation and auscultation whenever practicable. Where a breathing circuit is used, the reservoir bag should be observed. Continuous monitoring with a precordial, pretracheal, or oesophageal stethoscope is RECOMMENDED. Confirmation of the correct placement of an endotracheal tube and also the adequacy of ventilation by continuous measurement and display of the expired carbon dioxide waveform and concentration (capnography) is RECOMMENDED. When mechanical ventilation is employed, a "disconnect alarm" should be used throughout the period of mechanical ventilation. Continuous measurement of the inspiratory and/or expired gas volumes, and of the concentration of volatile agents, is Suggested.

\section{Circulation}

\section{(i) Cardiac rate and rhythm}

The circulation should be monitored continuously. Palpation or display of the pulse and/or auscultation of the heart sounds should be continuous. Continuous monitoring and display of the heart rate with a pulse oximeter is HIGHLY RECOMMENDED; an 


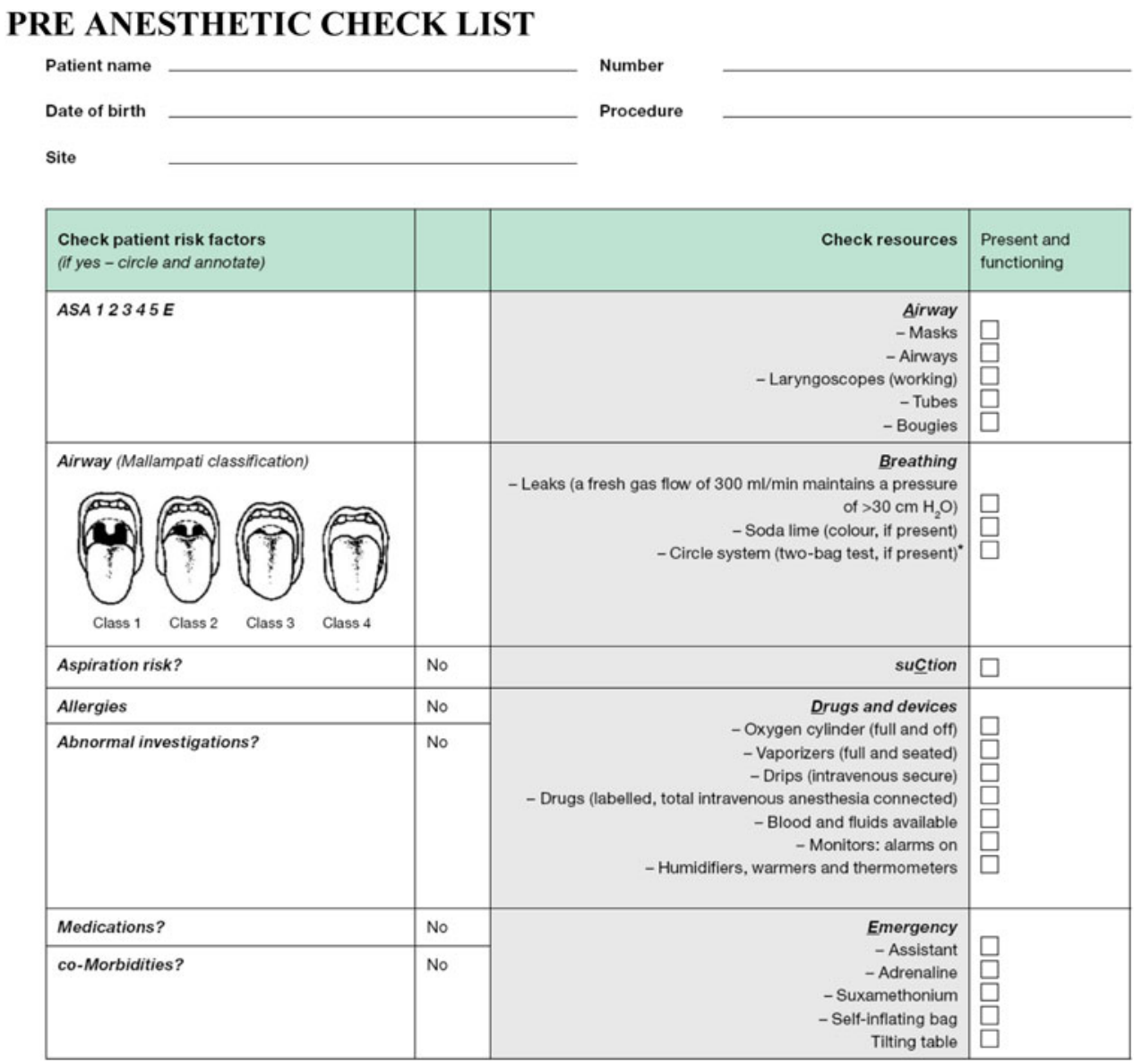

\begin{abstract}
*The integrity of a circle system and its valves should be checked by placing one breathing bag in the correct place for ventilating a patient and another breathing bag on the patient limb of the Y-piece (i.e. in place of the patient) and ventilating the system manually using an appropriate fresh gas flow and squeezing the primary and secondary bags alternatively, so that gas passes around the circle from one to the other. Inflation and deflation of the breathing bag, movement of any visible unidirectional valves, and the resistance and compliance of the system should all be assessed as "normal". The function of the adjustable pressure limiting valve should also be checked by spilling some of the gas when both bags are compressed. This "two bag check" is a reliable way of detecting expiratory limb obstruction which is readily missed when less systematic checks of the integrity of the circuit are carried out.
\end{abstract}

electrocardiograph is RECOMMENDED. The availability of a defibrillator is RECOMMENDED.

\section{(ii) Tissue perfusion}

The adequacy of tissue perfusion should be monitored continually by clinical examination. Continuous monitoring with a pulse oximeter is HIGHLY RECOMMENDED; continuous monitoring with a capnograph is RECOMMENDED.

\section{(iii) Blood pressure}

Arterial blood pressure should be determined at appropriate intervals (usually at least every 5 minutes and more frequently if indicated by clinical circumstances). Automated non-invasive blood pressure measurements have many advantages in anesthesia; continuous measurement and display of arterial pressure is Suggested in appropriate cases.

\section{Temperature}

A means of measuring the temperature should be available and should be used at frequent intervals where clinically indicated (e.g. prolonged or complex anesthetics, young children). The continual measurement of temperature in patients in whom a change is anticipated, intended, or suspected is RECOMMENDED. The availability and use of continuous electronic temperature measurement is Recommended. 


\section{E. Neuromuscular function}

When neuromuscular blocking drugs are given, the use of a peripheral nerve stimulator is RECOMMENDED.

F. Depth of anesthesia

The depth of anesthesia (degree of unconsciousness) should be regularly assessed by clinical observation. The continuous measurement of inspired and expired concentrations of anesthetic gases and volatile agents is Suggested. The application of an electronic device intended to measure brain function (consciousness), while controversial and not universally recommended, should be considered, particularly in cases with high risk of awareness under general anesthesia.

\section{G. Audible signals and alarms}

Available audible signals (such as the variable pitch pulse tone of the pulse oximeter) and audible alarms (with appropriately set limit values) should be activated at all times and loud enough to be heard throughout the operating room.

\section{Post-anesthesia care}

\section{A. Facilities and personnel}

All patients who have had an anesthetic affecting central nervous system function and/or a loss of protective reflexes should remain where anesthetized until recovered or be transported safely (with care and monitoring as indicated) to a specifically designated recovery location for post-anesthesia recovery. See General Standards, Section 7, for delegation of responsibilities to dedicated qualified recovery personnel.

\section{B. Monitoring}

All patients should be observed and monitored in a manner appropriate to the state of their nervous system function, vital signs, and medical condition with emphasis on the adequacy of oxygenation, ventilation, circulation, and temperature. Supplementation of clinical monitoring with quantitative methods analogous to intraanesthetic patient care described above is RECOMMENDED. Specifically, pulse oximetry is HIGHLY RECOMMENDED until consciousness has recovered (i.e. the patient is no longer anesthetized).

C. Pain relief

All patients are entitled to appropriate efforts to prevent and alleviate postoperative pain employing available appropriate medications and modalities; these efforts are therefore HIGHLY RECOMMENDED. Usually, the involved anesthesia professional assumes initial responsibility for this.

Permissions and acknowledgements With permission from the Department of Knowledge Management and Sharing of the World Health Organization, these Standards incorporate and elaborate upon components of: WHO Guidelines for Safe Surgery. Safe Surgery Saves Lives. WHO Press: World Health Organization, Geneva, 2009. http://whqlibdoc.who.int/publications/2009/9789241598552_eng.pdf (accessed 25th June 2010).

The Preanesthetic Checklist is an exact reproduction of Figure 2.1 of this publication.

The Table has been adapted from: Surgical Care at the District Hospital. World Health Organization, Geneva, 2003 http://whqlibdoc. who.int/publications/2003/9241545755.pdf (accessed 25 ${ }^{\text {th }}$ June 2010), and from: International Taskforce on Anaesthesia Safety. International standards for a safe practice of anaesthesia. European Journal of Anaesthesiology 1993; 10 (Suppl 7): 12-15.

The Authors thank Dr M.N. Cherian for her invaluable contribution as a member of the Safe Anesthesia Working Group to the development of the Standards. The authors gratefully acknowledge the support and input of Dr. Atul Gawande and the other leaders of the WHO "Safe Surgery Saves Lives" program (notably Drs G. Dziekan, W.R. Berry, T.G. Weiser and A.B. Haynes), as well as the constant encouragement and facilitation by the WFSA leadership, particularly current WFSA President Dr. Angela Enright.

Conflicts of interest A. F. Merry has financial interests in Safer Sleep LLC.

Open Access This article is distributed under the terms of the Creative Commons Attribution Noncommercial License which permits any noncommercial use, distribution, and reproduction in any medium, provided the original author(s) and source are credited. 